ISSN: $2338-4794$

Vol.6. No. 2 Mei-Agustus 2018

\title{
PENGARUH KUALITAS LAYANAN JASA DAN HARGA TERHADAP KEPUASAN PELANGGAN PT. BUKITAPIT BUMI PERSADA
}

\author{
Melya Fitriyana ${ }^{1)}$ \\ 1) Mahasiswa Program Studi Manajemen FE UNKRIS \\ Donny Dharmawan ${ }^{2)}$ \\ 2) Dosen Program Studi Manajemen FE UNKRIS \\ Alamat: Kampus UNKRIS, Jatiwaringin Jakarta Timur \\ Email : donny28dh@gmail.com
}

\begin{abstract}
PT. Bukitapit Bumi Persada is one of the first local companies in the field of oil and gas industry services in Indonesia. One of the advantages is, $100 \%$ percent locally owned and utilization of local resources, so that PT. Buktapit Bumi Persada is able to compete with other foreign companies. PT. Bukitapit Bumi Perasada currently serves not only local oil companies (Pertamina), but also has completed several projects with other oil companies. This study aims to analyze the effect of service quality and price policy on customer satisfaction at PT Bukitapit Bumi Persada. The population and sample of the research were 31 clients and the technique used in the research was non probability sampling with saturated sampling.

The results showed that service quality and pricing policies affect customer satisfaction PT. Perasada Earth Bukitapit.
\end{abstract}

Keywords: Service Quality, Price Policy and Customer Satisfaction

\section{PENDAHULUAN}

Di tengah persaingan yang ketat menghadapi gempuran perusahaan asing yang menguasai migas di Indonesia, perusahaan lokal kini tengah berjuang keras untuk dapat bersaing untuk mensejajarkan posisinya dengan korporasi asing. Dengan memperbaiki kualitas pelayanan, meningkatkan sumber daya manusia dan mengutamakan aspek keselamatan kerja, kini perusahaan lokal mampu mengambil perannya di negerinya sendiri. Hampir seluruh perusahaan jasa ingin dipersepsikan sebagai perusahaan yang memiliki reputasi atau citra yang kuat seperti kualitas pelayanan jasa yang baik dan harga yang bersaing. Atribut-atribut ini yang digunakan oleh perusahaan jasa untuk mendapatkan eksistensi di benak kliennya. Pengambilan basis posisi tersebut tampaknya dilandasi oleh pandangan bahwa reputasi yang baik adalah modal utama untuk memperoleh kepercayaan dari klien yang merupakan modal penting dari strategi marketing.

Merosotnya harga minyak perlu diperhatikan oleh perusahaan minyak dan gas agar dapat memperluas fokus utamanya, yaitu berhasil melewati serangkaian hambatan yang terus berkembang. Namun meskipun halaman berita utama terus mendominasi mengenai harga minyak yang terus tertekan, masa depan industri patut dipertimbangkan untuk mengetahui seberapa besar kekuatan perusahaan dalam melewati tantangan ini.

Banyak sekali gangguan lain yang dihadapi dari sektor ini, permintaan global akan terus tumbuh di masa depan untuk energi yang terjangkau dan dapat diandalkan. Berjalannya waktu dan perhitungan keuntungan dari segi keekonomian maka sumur yang mengalami permasalahan yang bisa menurunkan laju produksi minyak dan gas bumi harus ditanggulangi supaya laju 
produksi bisa meningkat kembali atau dengan kata lain bahwa sumur bisa berproduksi dalam keadaan normal kembali.

Seiring berjalannya transisi dunia menuju sistem rendah karbon, perusahaan minyak dan gas perlu untuk mempertimbangkan masa depan mereka untuk menggantikan bahan bakar fosil dengan sumber energi yang lebih baik dan lebih bersih agar semakin meningkat.

Salah satu frase yang tepat untuk menyebut pemerintahan 2014-2019 adalah Pemerintahan Minyak. Atau bisa disebut Oil Government, maka dapat dikatakan bahwa pada 2014 - 2019, pemimpin yang tepat harus mengerti ekonomi dan energi.

\section{LANDASAN TEORI}

\section{Kualitas Layanan}

Definisi kualitas pelayanan dapat diartikan sebagai upaya pemenuhan kebutuhan dan keinginan konsumen serta ketepatan penyampaiannya dalam mengimbangi harapan konsumen (Tjiptono, 2014). PT. Bukitapit Bumi Persada menciptakan nilai tambah dengan meningkatkan kualitas pelayanan jasa seperti memberikan pelayanan yang berkualitas serta waktu operasional yang tepat sehingga kebutuhan klien pun dapat terpenuhi. Dengan pelaksanaan pekerjaan terencana dengan baik dan hasil pekerjaan tersebut baik maka klien pun dapat terpuaskan sehingga klien tetap setia dan tidak berpindah ke perusahaan lain.

Tjiptono (2010) yang mengatakan bahwa kualitas jasa adalah tingkat keunggulan yang diharapkan dan pengendalian atas tingkat keunggulan tersebut untuk memenuhi keinginan pelanggan". Sedangkan menurut Mauludin (2010) mengemukakan bahwa kualitas pelayanan adalah seberapa jauh perbedaan antara kenyataan dan harapan pelanggan atas langganan yang mereka terima atau peroleh.

Menurut Sunyoto (2012), "Mutu pelayanan berpusat pada upaya pemenuhan kebutuhan dan keinginan konsumen serta ketepatan penyampaiannya untuk mengimbangi harapan konsumen, yaitu adanya kesesuaian antara harapan dengan persepsi manajemen, adanya kesesuaian antara persepsi atas harapan konsumen dengan standar kerja karyawan, adanya kesesuaian antara standar kerja karyawan dengan pelayanan yang diberikan dengan pelayanan yang dijanjikan dan adanya kesesuaian antara pelayanan yang diterima dengan yang diharapkan dengan konsumen".

Dari definisi-definisi tentang kualitas pelayanan tersebut dapat diambil kesimpulan bahwa kualitas pelayanan adalah segala bentuk aktivitas yang dilakukan oleh perusahaan guna memenuhi harapan konsumen. Pelayanan dalam hal ini diartikan sebagai jasa atau service yang disampaikan oleh pemilik jasa yang berupa kemudahan, kecepatan, hubungan, kemampuan dan keramahtamahan yang ditujukan melalui sikap dan sifat dalam memberikan pelayanan untuk kepuasan pelanggan.

\section{Harga}

Harga merupakan komponen penting atas suatu produk, karena akan berpengaruh terhadap keuntungan produsen. Harga juga menjadi pertimbangan konsumen untuk membeli, sehingga perlu pertimbangan khusus untuk menentukan harga tersebut. Menurut Harini (2008) "harga adalah uang (ditambah beberapa produk kalau mungkin) yang dibutuhkan untuk mendapatkan sejumlah kombinasi dari produk dan pelayanannya." Hasan (2009) juga mengungkapkan "harga merupakan segala bentuk biaya moneter yang dikorbankan oleh konsumen untuk memperoleh, memiliki, memanfaatkan 
sejumlah kombinasi dari barang beserta pelayanan dari suatu produk."

$$
\text { Menurut Widjaja (2009) }
$$

mengutarakan bahwa "pricing strategy dapat dilakukan dengan berbagai pemilihan strategi dan mempertimbangkan juga berbagai elemen lainnya seperti tingkat fungsional psikologi jasa yang ditawarkan, tingkat persaingan, produk dan jasa yang ditawarkan, target market, kombinasi product service dan cost based."

Buchory (2010) mengatakan dalam pasar yang konsumennya sangat sensitif terhadap harga, bila suatu perusahaan menurunkan harganya, maka parapesaingnya harus menurunkan pula harga mereka dalam menetapkan harga untuk mempertahankan hubungan yang stabil antara harga suatu perusahaan dan harga pemimpin perusahaan yang menjadi leader.

Berdasarkan pengertian-pengertian dari para ahli pemasaran diatas, maka diperoleh penjelasan bahwa pricing strategy merupakan salah satu dari unsur bauran pemasaran yang menghasilkan pendapatan dan akan mempengaruhi kuantitas dari tingkat harga yang ditetapkan

Menurut Machfoedz (2005) "penetapan harga dipengaruhi oleh berbagai faktor, baik faktor internal maupun faktor eksternal. Faktor internal meliputi tujuan pemasaran perusahaan, strategi bauran pemasaran, biaya, dan metode penetapan harga." Faktor eksternal meliputi sifat pasar dan permintaan, persaingan, dan elemen lingkungan yang lain.

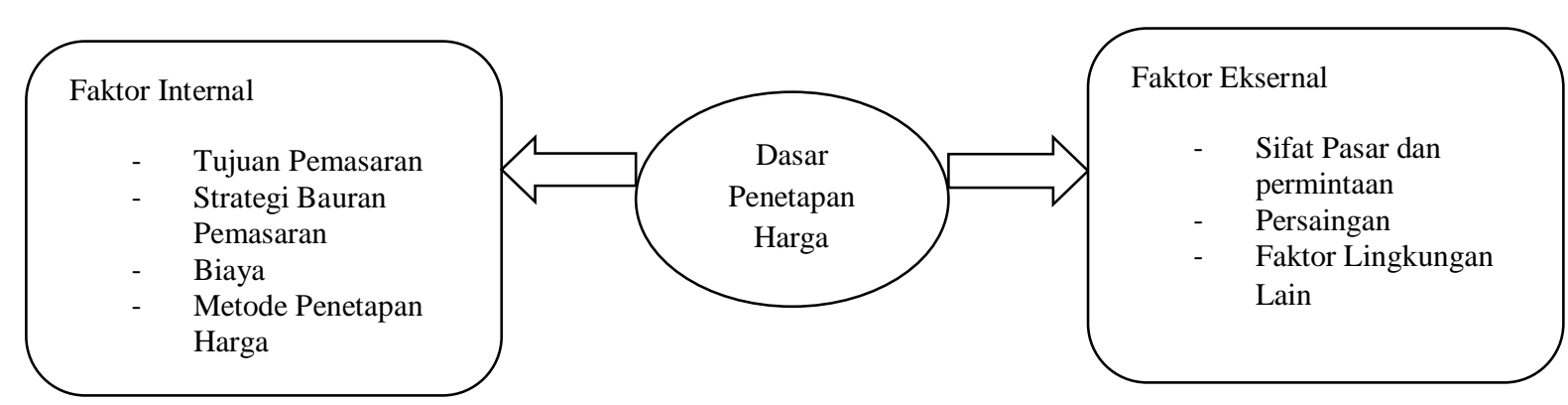

\section{Gambar 1. Principles of Marketing \\ Sumber: Kotler \& Amstrong (2012)}

\section{Kepuasan Pelanggan}

Definisi kepuasan pelanggan menurut Kotler (2014) ialah: Perasaan senang atau kecewa yang muncul setelah membandingkan kinerja (hasil) produk yang dipikirkan terhadap kinerja (atau hasil) yang diharapkan. Sedangkan menurut Mohsan (2011) mengungkapkan bahwa kepuasan adalah keseluruhan dari sikap atau perilaku pelanggan terhadap pelayanan yang diberikan, atau sebuah reaksi emosional perbedaan antara apa yang diharapkan pelanggan dengan apa yang diterima mengenai pemenuhan beberapa kebutuhan, keinginan dan tujuan.

\section{METODE PENELITIAN}

\section{Populasi dan Sampel}

Dalam penelitian ini populasi dari klien PT. Bukitapit Bumi Persada sebanyak 31 klien. Tehnik yang digunakan dalam penelitian ini adalah non probability sampling dengan pendekatan sampling jenuh. Sampling jenuh merupakan tehnik penentuan sampel bila semua anggota populasi dijadikan sebagai sampel. Hal ini dikarenakan jumlah populasi kecil atau kurang dari 31. Istilah lain dari sampel jenuh adalah sensus, dimana semua anggota populasi dijadikan sampel. 


\section{Teknik Analisis Data}

Analisis regresi linier beganda adalah hubungan secara linear antara satu variabel independen $(\mathrm{X})$ dengan variabel dependen (Y).

\section{HASIL PENELITIAN DAN PEMBAHASAN}

\section{Hasil Penelitian Uji Validitas}

Pengujian validitas ini dilakukan untuk menguji apakah tiap-tiap butir pernyataan telah mewakili indikator yang diselidiki. Validitas pengukuran syarat minimum untuk dianggap valid adalah $\mathrm{r}$ $=0.30$. maka apabila korelasi antara butir- butir item pernyataan dengan skor total kurang dari 0,30 maka butiran dalam instrument tersebut dinyatakan tidak valid. Uji validitas dilakukan dengan melihat korelasi antara masing- masing item pernyataan dengan skor total.

\section{Uji Validitas Instrumen Kualitas Layanan}

Dari hasil penghitungan koefisien korelasi skor tiap butir pernyataan instrument kompetensi dari 31 responden, dengan jumlah 9 (Sembilan) pertanyaan dengan total skor setiap responden diperoleh hasil disajikan dalam tabel sebagai berikut:

Tabel 1. Uji Validitas Variabel Kualitas Layanan

\begin{tabular}{cccc}
\hline Pertanyaan & R Hitung & R Kritis & Kesimpulan \\
\hline Instrumen No. 1 & 0,538 & 0,300 & Valid \\
Instrumen No. 2 & 0,396 & 0,300 & Valid \\
Instrumen No. 3 & 0,606 & 0,300 & Valid \\
Instrumen No. 4 & 0,416 & 0,300 & Valid \\
Instrumen No. 5 & 0,549 & 0,300 & Valid \\
Instrumen No. 6 & 0,531 & 0,300 & Valid \\
Instrumen No. 7 & 0,358 & 0,300 & Valid \\
Instrumen No. 8 & 0,348 & 0,300 & Valid \\
Instrumen No. 9 & 0,553 & 0,300 & Valid \\
\hline
\end{tabular}

Sumber : Data diolah tahun 2017

Berdasarkan tabel 1 dapat dilihat setiap responden diperoleh dari hasil bahwa 9 butir pertanyaan dari variabel disajikan dalam tabel berikut ini:

kualitas layanan adalah valid.

\section{Uji Validitas Instrumen Kebijakan Harga}

Dari hasil penghitungan koefisien korelasi skor tiap butir pertanyaan instrument kompensasi dari 31 responden, dengan jumlah pertanyaan sebanyak 9 Pertanyaan dengan total skor 
Tabel 2. Uji Validitas Variabel Kebijakan Harga

\begin{tabular}{cccc}
\hline Pertanyaan & R Hitung & R Kritis & Kesimpulan \\
\hline Instrumen No. 1 & 0,303 & 0,300 & Valid \\
Instrumen No. 2 & 0,419 & 0,300 & Valid \\
Instrumen No. 3 & 0,494 & 0,300 & Valid \\
Instrumen No. 4 & 0,545 & 0,300 & Valid \\
Instrumen No. 5 & 0,372 & 0,300 & Valid \\
Instrumen No. 6 & 0,419 & 0,300 & Valid \\
Instrumen No. 7 & 0,392 & 0,300 & Valid \\
Instrumen No. 8 & 0,401 & 0,300 & Valid \\
Instrumen No. 9 & 0,475 & 0,300 & Valid \\
\hline
\end{tabular}

Sumber : Data diolah tahun 2017

Berdasarkan Tabel 2 dapat dilihat bahwa 9 butir pertanyaan dari variabel kebijakan harga adalah valid.

\section{Uji Validitas Instrumen Kepuasan Pelanggan}

Tabel 3. Uji Validitas Variabel Kepuasan Pelanggan

\begin{tabular}{cccc}
\hline Pertanyaan & R Hitung & R Kritis & Kesimpulan \\
\hline Instrumen No. 1 & 0,591 & 0,300 & Valid \\
Instrumen No. 2 & 0,319 & 0,300 & Valid \\
Instrumen No. 3 & 0,350 & 0,300 & Valid \\
Instrumen No. 4 & 0,536 & 0,300 & Valid \\
Instrumen No. 5 & 0,686 & 0,300 & Valid \\
Instrumen No. 6 & 0,623 & 0,300 & Valid \\
Instrumen No. 7 & 0,396 & 0,300 & Valid \\
Instrumen No. 8 & 0,489 & 0,300 & Valid \\
Instrumen No. 9 & 0,330 & 0,300 & Valid \\
\hline
\end{tabular}

Sumber : Data diolah tahun 2017

Berdasarkan tabel 3 dapat dilihat bahwa semua variabel dalam penelitian ini dapat diandalkan. bahwa 9 butir pertanyaan dari variabel kepuasan pelanggan adalah valid.

\section{Uji Realibilitas}

Selanjutnya dilakukan uji reliabiltas untuk mengetahui sejauh mana hasil pengukurannya dapat diandalkan dan konsisten. Pada tabel hasil pengujian berikut diketahui bahwa semua variabel mempunyai alpha diatas 0.6 yang berarti 
Tabel 4. Uji Validitas Reliabilitas

\begin{tabular}{lccc}
\hline \multicolumn{1}{c}{ Variabel } & Koefisien Alpha (a) & Nilai Kritis $(\boldsymbol{\alpha})=\mathbf{5 \%}$ & Keterangan \\
\hline Kualitas Layanan & 0,777 & 0,600 & Reliabel \\
Harga & 0,747 & 0,600 & Reliabel \\
Kepuasan Pelanggan & 0,791 & 0,600 & Reliabel \\
\hline
\end{tabular}

Sumber : Data diolah tahun 2017

Berdasarkan tabel 4 dapat diketahui bahwa masing-masing variabel antara variabel kualitas pelayanan, harga dan kepuasan pelanggan, ternyata diperoleh nilai Cronbach Alpha $\geq 0,60$. Dengan demikian dapat disimpulkan bahwa data kuesioner yang peneliti gunakan dalam penelitian ini sudah sangat representatif dalam arti kata pengukuran datanya sudah dapat dipercaya (reliabel). Setelah dilakukan pengujian instrumen yang mana hasilnya menyatakan bahwa data penelitian adalah valid dan reliabel.

\section{Uji Hipotesis}

1. Analisis Pengaruh Kualitas layanan dan Harga terhadap Kepuasan Pelanggan

Tabel 5. Hasil Analisis Pengaruh Kualitas layanan dan Harga Terhadap Kepuasan Pelanggan

\begin{tabular}{ccccccc}
\hline $\begin{array}{c}\text { Hubungan } \\
\text { Variabel }\end{array}$ & $\begin{array}{c}\text { Mult. } \\
\text { R }\end{array}$ & $\begin{array}{c}\text { R } \\
\text { Square }\end{array}$ & $\begin{array}{c}\text { Kons } \\
\text { tanta }\end{array}$ & Coef. B & Sig & $\alpha$ \\
\hline $\begin{array}{c}\text { Pelayanan. } \\
\text { Harga }\end{array}$ & $\mathbf{0 . 8 8 7}$ & $\mathbf{0 . 7 8 6}$ & $\mathbf{2 . 0 1 9}$ & $\begin{array}{c}\mathbf{0 . 6 7 4} \\
\mathbf{0 . 3 6 6}\end{array}$ & $\mathbf{0 . 0 0 0}$ & $\mathbf{5 \%}$ \\
Pengujian Signifikan & & & & & \\
\hline F hitung > F Tabel = 86.291 > 3.195 & & & & \\
\hline
\end{tabular}

a. Predictors: (Consultant), Harga, Pelayanan

b. Dependent Variable: Kepuasan

Koefisien

menunjukkan besarnya kemampuan kualitas pelayanan sebagai variabel independen dalam memberikan kontribusi kepada kepuasan pelanggan sebagai variabel dependen. Nilai koefisien determinasinya $\left(\mathrm{R}^{2}\right)$ dari data tersebut adalah 0,786 , artinya sumbangan yang diberikan variabel kualitas layanan dan harga kepada variabel kepuasan pelanggan sebesar $78,6 \%$, sisanya sebesar $21,4 \%$ disumbangkan variabel lain yang tidak diteliti.

Pengujian secara simultan kualitas pelayanan dan harga terhadap kepuasan pelanggan signifikannya atau tidak, dilakukan pengujian $F$ hitung dibandingkan $\mathrm{F}$ tabel atau dengan signifikansi Prob. dengan tingkat kepercayaan $\alpha(\mathrm{P}=0.000$, untuk $\mathrm{a}=0,05)$. Dari output diatas, diperoleh nilai $\mathrm{F}$ hitung sebesar 86,291 dan untuk membandingkan dengan nilai $\mathrm{F}$ tabelnya dapat dicari dengan rumus mencari $\mathrm{F}$ tabel adalah $(\mathrm{k} ; \mathrm{n}-\mathrm{k})$, dimana: $\mathrm{k}$ (jumlah variabel independen/bebas) dan $\mathrm{n}$ (jumlah Responden), maka dengan melihat data diatas dimana $\mathrm{k}=2$ (kualitas pelayanan, harga) dan $\mathrm{n}=31$ dapat dihitung dengan rumus $(2 ; 31-2)=(2 ; 29)$ dan dapat dilihat 
pada $\mathrm{F}$ tabel bahwa $(2 ; 29)$ sebesar 3,33, bila $\mathrm{F}$ hitung dibandingkan dengan $\mathrm{F}$ tabel 86,291>3,333 maka dapat diketahui $\mathrm{F}$ hitung lebih besar dari $\mathrm{F}$ tabel maka dapat di tarik kesimpulan bahwa variabel kualitas pelayanan dan variabel harga (secara simultan) berpengaruh terhadap kepuasan pelanggan.

\section{Analisis Pengaruh Kualitas Pelayanan terhadap Kepuasan Pelanggan}

Tabel 6. Koefisien Determinasi Kualitas Pelayanan

\begin{tabular}{ccccccc}
\hline \multirow{2}{*}{$\begin{array}{c}\text { Hubungan } \\
\text { Variabel }\end{array}$} & $\begin{array}{c}\text { Mult. } \\
\text { R }\end{array}$ & $\begin{array}{c}\text { R } \\
\text { Square }\end{array}$ & $\begin{array}{c}\text { Kons } \\
\text { tanta }\end{array}$ & Coef. B & Sig & $\alpha$ \\
\hline Pelayanan. & $\mathbf{0 . 8 9 1}$ & $\mathbf{0 . 8 2 9}$ & $\mathbf{4 . 8 8 0}$ & $\mathbf{0 . 8 2 7}$ & $\mathbf{0 . 0 0 0}$ & $\mathbf{5 \%}$
\end{tabular}

Pengujian Signifikan

t hitung $>\mathrm{t}$ tabel $=9.971>2.035$

a. Dependent Variable: Kepuasan

Koefisien determinasi menunjukkan besarnya kemampuan kualitas pelayanan sebagai variabel independen dalam memberikan kontribusi kepada kepuasan pelanggan sebagai variabel dependen. Nilai koefisien determinasinya $\left(\mathrm{R}^{2}\right)$ dari data tersebut adalah 0,829 , atau bisa dikatakan bahwa variabel ini memberi sumbangan pengaruh sebanyak $82 \%$ dan $18 \%$ dipengaruhi oleh faktor -faktor diluar kualitas pelayanan. Koefisien regresi bernilai 0,829. Artinya, jika ada peningkatan pelayanan sebanyak 1 kali, maka kepuasan pelanggan juga akan meningkat 0,829 kali.

\section{Analisis Pengaruh Harga terhadap Kepuasan Pelanggan}

Dan untuk menguji hubungan secara parsial variabel kualitas pelayanan terhadap kepuasan pelanggan signifikan atau tidak, dilakukan pengujian $t$ hitng dibandingkan dengan $\mathrm{t}$ tabel dengan tingkat $\mathrm{a}=0.05$, hasilnya adalah $\mathrm{t}$ tabel $=$ 2,035 yang dilihat dari tabel distribusi $t$ (derajat kebebasan $=n-2 \quad(31-2=29)$, dengan uji dua sisi). Berdasarkan perhitungan terebut diatas dapat dinyatakan bahwa nilai t hitung $=9,971$ dan $\mathrm{t}$ tabel $=2,035$ atau $\mathrm{t}$ hitung lebih besar dari t tabel $(9,971>2,035)$, maka dapat diartikan terdapat pengaruh yang signifikan variabel kualitas pelayanan terhadap kepuasan pelanggan. 
Tabel 7. Koefisien Determinasi Harga

\begin{tabular}{ccccccc}
\hline \multirow{2}{*}{$\begin{array}{c}\text { Hubungan } \\
\text { Variabel }\end{array}$} & $\begin{array}{c}\text { Mult. } \\
\mathbf{R}\end{array}$ & $\begin{array}{c}\mathbf{R} \\
\text { Square }\end{array}$ & $\begin{array}{c}\text { Karameter } \\
\text { tanta }\end{array}$ & Coef. B & Sig & $\alpha$ \\
\hline Harga & $\mathbf{0 . 6 3 7}$ & $\mathbf{0 . 4 0 5}$ & $\mathbf{1 5 . 3 5 5}$ & $\mathbf{0 . 6 4 6}$ & $\mathbf{0 . 0 0 0}$ & $\mathbf{5 \%}$ \\
& & & & & \\
\hline
\end{tabular}

Koefisien determinasi menunjukkan besarnya kebijakan harga yang ditawarkan sebagai variabel independen dalam memberikan kontribusi kepada kepuasan pelanggan sebagai variabel dependen. Nilai koefisien determinasinya $\left(\mathrm{R}^{2}\right)$ dari data tersebut adalah 0,405, atau bisa dikatakan bahwa variabel ini memberi sumbangan pengaruh sebanyak $40 \%$ dan $60 \%$ dipengaruhi oleh faktor -faktor diluar harga.

Dan untuk menguji hubungan secara parsial variabel harga terhadap kepuasan pelanggan signifikan atau tidak, dilakukan pengujian $t$ hitung dibandingkan dengan $\mathrm{t}$ tabel dengan tingkat $\mathrm{a}=0.05$, hasilnya adalah $\mathrm{t}$ tabel $=$ 2,035 yang dilihat dari tabel distribusi $t$ (derajat kebebasan $=\mathrm{n}-2$ (31$2=29$ ), dengan uji dua sisi). Berdasarkan perhitungan terebut diatas dapat dinyatakan bahwa nilai t hitung $=2,150$ dan $\mathrm{t}$ tabel $=2,035$ atau $\mathrm{t}$ hitung lebih besar dari t tabel $(9,403>2,035)$, maka dapat diartikan terdapat pengaruh yang signifikan variabel kebijakan harga terhadap kepuasan pelanggan.

\section{Pembahasan}

\section{Pengaruh Kualitas Layanan Terhadap Kepuasan Pelanggan}

PT. Bukitapit Bumi Persada memberikan kualitas pelayanan yang terbaik agar mendapat nilai positif di mata konsumen. Kualitas pelayanan tersebut dapat berupa bukti konkret kemampuan suatu perusahaan, yaitu fisik tampilan bangunan, fasilitas danperlengkapan teknologi pendukung hingga penampilan karyawan.

Peralatan dan perlengkapan yang safety tentu menjadi standar bagi BBP dalam memberikan kualitas pelayanan terhadap konsumen. Setiap pekerjaan mengutamakan adanya kesehatan dan keselamatan kerja (K3). K3 ini terkait dengan kesehatan, keselamatan dan kesejahteraan manusia yang bekerja di sebuah instansi maupun lokasi proyek. BBP dalam melaksanakan usahanya bertanggung jawab melindungi keselamatan dan kesehatan karyawan, mitra kerja dan keluarganya serta masyarakat dan mengusahakan perlindungan terhadap lingkungan.

Disamping itu, BBP mengembangkan budaya yang mendorong karyawan untuk melakukan komunikasi secara terbuka sehubungan dengan masalah-masalah keselamatan, kesehatan dan lindungan lingkungan. Hal ini dapat mencegah terjadinya kecelakaan kerja dan kerusakan lingkungan agar kegiatan operasi dapat dilaksanakan dengan aman. Hal inilah yang menjadikan salah satu keunggulan BBP dibanding kompetitor lainnya.

\section{Pengaruh Harga Terhadap Kepuasan Pelanggan}

PT. Bukitapit Bumi Persada harus memperhitungkan biaya pesaing, harga pesaing dan kemungkinan reaksi harga oleh pesaing. Jika tawaran perusahaan serupa dengan tawaran pesaing utamanya, maka perusahaan harus menetapkan harga yang dekat dengan 
harga pesaing atau perusahaan tersebut akan kehilangan penjualan. Jika tawaran perusahaan lebih rendah mutunya, perusahaan tidak dapat menetapkan harga yang lebih tinggi dari pada pesaing. Jika penawaran perusahaan lebih tinggi mutunya, perusahaan dapat menetapkan harga yang lebih tinggi dari pada pesaing. Akan tetapi perusahaan harus menyadari bahwa pesaing dapat mengubah harganya sebagai tanggapan atas harga perusahaan.

Metode penetapan harga yang paling dasar adalah dengan menambah mark up standar ke biaya produk, yaitu memberikan harga tender dengan memperkirakan biaya total proyek dan menambahkan markup standar sebagai laba. Selain itu PT. Bukitapit Bumi Persada juga menetapkan harga yang cukup rendah untuk tawaran yang bermutu tinggi, penetapan harga sesuai harga berlaku (going-rate pricing) serta melakukan penetapan harga yang kompetitif jika perusahaan mengikuti tender tertutup atas suatu proyek. Perusahaan menentukan harga berdasarkan perkiraannya tentang bagaimana pesaing akan menetapkan dan bukan berdasarkan hubungan yang kaku dengan biaya atau permintaan perusahaan. Maka dapat disimpulkan bahwa kebijakan harga yang diberikan sangat berpengaruh besar terhadap pengambilan keputusan oleh konsumen sehingga BBP dapat memenangkan persaingan pasar dari kompetitor lainnya.

Kepuasan pelanggan sangat tergantung pada persepsi dan harapan pelanggan itu sendiri. Dalam jangka panjang, akan lebih menguntungkan mempertahankan pelanggan, karena pelanggan yang sangat puas akan menyebarkan cerita positif dari mulut ke mulut. Kepuasan pelanggan PT. Bukitapit Bumi Persada dapat menciptakan keunggulan yang berkelanjutan, mendorong pelanggan kembali dan loyalitas, mengisolasi pelanggan dari persaingan dan mengurangi biaya kegagalan serta menurunkan biaya untuk menarik pelanggan baru. Jadi dapat disimpulkan bahwa kepuasan konsumen itu sendiri dapat mempengaruhi loyalitas pelanggan.

\section{KESIMPULAN DAN SARAN}

\section{Kesimpulan}

Berdasarkan uraian di atas dapat disimpulkan sebagai berikut : 1). Berdasarkan hasil penelitian secara simultan variabel kualitas pelayanan dan harga berpengaruh secara positif dan signifikan terhadap kepuasan pelanggan PT. Bukitapit Bumi Persada, 2). Berdasarkan hasil penelitian secara parsial variabel kualitas pelayanan berpengaruh secara positif dan signifikan terhadap kepuasan pelanggan PT. Bukitapit Bumi Persada. 3). Berdasarkan hasil penelitian secara parsial variabel harga berpengaruh secara positif dan signifikan terhadap kepuasan pelanggan PT. Bukitapit Bumi Persada.

\section{Saran}

Saran yang dapat diberikan adalah: 1). Untuk memperbaiki sistem kualitas pelayanan, sebaiknya penguasaan teknologi dan alat-alat canggih ditingkatkan, memaksimalkan dan mempercepat dilakukannya pekerjaan di kontrak eksisting serta membenahi dan melengkapi kekurangan dokumen peralatan agar PT. Bukitapit Bumi Persada dapat menjadi perusahaan yang lebih baik lagi dimasa yang akan datang. 2). PT. Bukitapit Bumi Persada harus lebih berani bersaing dalam masalah harga dari kompetitor yang lain, sehingga PT. Bukitapit Bumi Persada dapat memenangkan persaingan pasar dari kompetitor lainnya.

\section{DAFTAR PUSTAKA}

Ali, Hasan, 2009, Marketing Edisi Baru, 
Alma, Buchari, 2010, Kewirausahaan, Bandung : Alfabeta

Amanah, Dita, 2010, Pengaruh Harga dan Kualitas Produk terhadap Kepuasan Konsumen pada Majestyk Backry Cake Shop Cabang H.M Yamin Medan, Jurnal Pendidikan Ekonomi, Vol2, Universitas Negeri Medan,

Basu, Swastha DH, Irawan. 2008, Manajemen Pemasaran Modern, Edisi Kedua, Cetakan Ke-tigabelas, Yogyakarta : Liberty Offset

Bernard T. Widjaja, 2009, Lifestyle Marketing: Paradigma Baru Pemasaran Bisnis Jasa, Jakarta : Gramedia Pustaka Utama

Buchory, Herry Achmad \& Djaslim Saladin, 2010, Manajemen Pemasaran, Bandung : Linda Karya

Cannon, Joseph P., William D. Perreault, and E. Jerome. McCarthy, 2008, Pemasaran Dasar-pendekatan manajemen global, Jakarta : Salemba Empat

Daryanto, 2011, Sari Kuliah Manajemen Pemasaran, Bandung : PT Sarana Tutorial Nurani Sejahtera

Faizan, Mohsan, 2011, Impact of Customer Satisfaction on Customer Loyalty and Intentions to Switch: Evidence from Banking Sector of Pakistan, International Journal of Business and Social Science, Vol 2 No 16 September 2011, Pp 263-270

Fandy, Tjiptono, 2011, Pemasaran Jasa, Malang : Bayumedia

Hardiansyah, 2011, Kualitas Pelayanan Publik, Yogyakarta : Gava Media

Harini, 2008, Makro Ekonomi Pengantar, Jakarta : PT Gramedia Pustaka Utama

Hutasoit, C.S, 2011, Pelayanan Publik Teori dan Aplikasi, Jakarta : Magna Script Publishing

Johnson dan Christensen, 2012, Educational Research, London : SAGE Publications, Inc
Kotler, Philip dan Kevin Lane Keller, 2012, Marketing Managemen, Edisi 14, Jakarta : Erlangga

Kotler, Philip \& Gary Armstrong, 2014, Principle Of Marketing, 15th edition, New Jersey : Pearson Prentice Hall

Lovelock, Chirstoper dan Jochen Wirtz. 2011. Service Marketing. New Jersey USA: Pearson

Machfoedz, Mahmud, 2005, Pengantar Pemasaran Modern, Yogyakarta : Upp Amp Ykpn

Notoatmodjo,S, 2005, Metodologi Penelitian Kesehatan, Jakarta : Rineka Cipta

Oliver, Richard L, 2007, Satisfaction, A Behavioral Perspective on The Customer New York : Mc GrawHill, Companies Inc

Stanton, William J., 2005, Prinsip Pemasaran, Jakarta : Penerbit Erlangga

Sugiyono. 2010. Metode Penelitian Pendidikan Pendekatan Kuantitatif, kualitatif, dan R\&D. Bandung: Alfabeta

Sunyoto, D, 2012, Manajemen Sumber Daya Manusia, Yogyakarta : CAPS

Susilo, Agus, 2010, Peningkatan Hasil Belajar Pendidikan Kewarganegaraan tentang Penanaman Nilai -Nilai Budi Pekerti Melalui Metode Bermain Peran pada Siswa Kelas III Sekolah Dasar Negeri 04 Karangrejo, Kecamatan Kerjo Kabupaten Karanganyar Semester I Tahun pelajaran 2009/2010, Skripsi, Surakarta : Fakultas Keguruan dan Ilmu Pendidikan UMS

Swayanti, Ika Putri, 2010, "Analisis Pengaruh Kualitas Produk, Kualitas Layanan, Harga, dan Tempat terhadap Keputusan Pembelian (Studi Pada Rumah Makan "Soto Angkring Mas Boed" 
di Semarang)", Skripsi, Semarang : Fakultas Ekonomi dan Bisnis, Universitas Diponegoro

Tjiptono, Fandy, 2010, Strategi Pemasaran, Edisi 2, Yogyakarta : Andi Offset

Tjiptono, Fandy, 2014, Strategi Pemasaran, Yogyakarta : Andi Offset
Tjiptono, Fandy dan Gregorius Chandra, 2012, Pemasaran Strategik, Yogyakarta : Andi

Zeithaml, V. A. And M. J. Bitner, 2010, Services Marketing, Fifth Edition, New York : The McGraw-Hill Companies Inc., p. 120

Zulian, Yamit, 2010. Manajemen Kualitas Produk \& Jasa, Vol. Edisi Pertama, Yogyakarta : EKONISIA 